\title{
GCU
}

Glasgow Caledonian

University

University for the Common Good

\section{Developing professional identity in nursing academics: the role of communities of practice}

Andrew, Nicky; Ferguson, Dorothy; Wilkie, George; Corcoran, Terry; Simpson, Liz

Published in:

Nurse Education Today

DOI:

10.1016/j.nedt.2009.01.012

Publication date:

2009

Document Version

Author accepted manuscript

Link to publication in ResearchOnline

Citation for published version (Harvard):

Andrew, N, Ferguson, D, Wilkie, G, Corcoran, T \& Simpson, L 2009, 'Developing professional identity in nursing academics: the role of communities of practice', Nurse Education Today, vol. 29, no. 6, pp. 607-611. https://doi.org/10.1016/j.nedt.2009.01.012

\section{General rights}

Copyright and moral rights for the publications made accessible in the public portal are retained by the authors and/or other copyright owners and it is a condition of accessing publications that users recognise and abide by the legal requirements associated with these rights.

Take down policy

If you believe that this document breaches copyright please view our takedown policy at https://edshare.gcu.ac.uk/id/eprint/5179 for details of how to contact us. 


\section{Title of Article}

DEVELOPING PROFESSIONAL IDENTITY IN NURSING ACADEMICS: THE ROLE OF COMMUNITIES OF PRACTICE

\section{Authors}

Dr Nicola Andrew (corresponding author)

Senior Lecturer

School of Nursing, Midwifery and Community Health

Glasgow Caledonian University

n.andrew@gcal.ac.uk

Dr Dorothy Ferguson

Head of Division

School of Nursing, Midwifery and Community Health

Glasgow Caledonian University

D.H.Ferguson@gcal.ac.uk

George Wilkie

Senior Lecturer

School of Nursing, Midwifery and Community Health

Glasgow Caledonian University

g.wilkie@gcal.ac.uk

Terry Corcoran

Senior Lecturer

School of Nursing, Midwifery and Community Health

Glasgow Caledonian University

t.corcoran@gcal.ac.uk

Liz Simpson

Lecturer 
School of Nursing, Midwifery and Community Health

Glasgow Caledonian University

E.Simpson@gcal.ac.uk

\section{Key Words}

Academic identity, Nursing, Communities of Practice

Word Count: 3,818

\section{Abstract}

This paper analyses the current standing of nursing within the wider United Kingdom (UK) higher education (HE) environment and considers the development of academic identity within the sector, introducing a technology mediated approach to professional learning and development. A community of practice $(\mathrm{CoP})$ is a way of learning based on collaboration among peers. Individuals come together virtually or physically, with a common purpose, defined by knowledge rather than task (Wenger 1998). In 2008, a small team of academics at Glasgow Caledonian University, School of Nursing, Midwifery and Community Health created and implemented $i C o P$, a project undertaken to pilot an international community of practice, where novices and expert academics collaborated to debate and discuss the complex transition from clinician to academic. Although not intended as a conventional research project, the developmental journey and emerging online discussion provide an insight into the collective thoughts and opinions of a multi-national group of novice academics. The article also highlights the key challenges, problems and limitations of working in an international online arena with professionals who traditionally work and thrive in a face to face, real time environment.

\section{Introduction}

Nursing in the UK has, within the past decade, moved into the HE sector; an arena that traditionally values theoretical and propositional knowledge rather than vocational and interpersonal skills (Miers 2002). There is a continuing reluctance within nursing to embrace 
an academic agenda. This may be a defensive reaction against a culture that by its vocational nature and defined practical activity is regarded as 'inferior to abstract thinking skills' (Miers 2002 p217) Communities of practice (CoPs) may have a contribution to make in the development of professional identity in education.

Lave and Wenger (1991) are credited with the original description of a CoP as an approach to learning that encompasses elements of identity, situation and active participation. Wenger's (1998) concept of a CoP is based on a social participative way of learning, developed within a situated learning environment. A CoP forms or is formed, around groups of people who share a common concern or interest and who wish to deepen their knowledge and expertise' in a particular subject or discipline The 'community acts as a vehicle for collaboration, allowing members to enter dynamic and engaged relationships with colleagues and others' (Wenger et al 2002 p4). Wenger (1998) suggests that individuals are motivated to join a CoP primarily to develop a sense of professional identity and belonging. McArthur-Rouse (2008) stresses the need for the development of professional identity, and Booth et al (2007) believe that to enable the development of practice, individuals need to explore of knowledge that is both tacit as well as explicit. Booth et al (2007) believe that a CoP provides a vehicle for the translation and transmission of tacit knowledge, thus aiding the development and understanding of professional behaviours in teaching. This model also has wider application; as CoPs pose a significant way forward for practising teachers to generate knowledge that will benefit the wider academic (national and international) community as a whole (Luby 2006/7).

\section{Is nursing an academic discipline?}

The question of whether or not nursing should be considered an academic discipline and the preparedness of nurses to enter Higher Education (HE) is fundamental to the question of how nurses manage their transition from practice to education and subsequently how they perceive their own professional standing within both. Miers (2002) states that within the UK, the migration from vocational training institutions (colleges of nursing) into HE was overwhelmingly viewed by former nurse tutors as conferring increased academic status. The assimilation of nursing into the sector was however viewed somewhat differently and at times negatively by the more established academic disciplines (Watson 2004). 
A tension exists between the institutional goal of research and the reality of the perceived priories of nurse academics (Andrew and Wilkie 2007). In nursing, in the UK, an increased emphasis on a skill based approach means that increasingly, knowledge development is seen 'more as the product of a technical process rather than of intellectual work' (Thompson 2006 p124). McNamara (2008) highlights the fact that in the UK, the entry of nursing into HE has provoked comment in both the literature and the media, much of which remains hostile to an aspirational academic nursing agenda. The enduring message appears to be that a university educated nurse cannot care for patients as well as one who has been 'trained' exclusively within the UK National Health Service and that somehow this omission 'lies at the heart of the present malaise' (Watson and Thomson 2004 p73). Part of the discourse of opposition expressed by McNamara (2008) describes nursing work as 'sacred but its essence is being corroded by the drive to academicise the non-academic' (p465). Doubts about the legitimacy of nursing as an academic discipline continue to prevail and consequently detract from the creation of a strong blueprint for the development of academia and academics. Butler et al (2006) suggest that nursing does not always appear on the academic radar because of its lack of specialist discourse, uniqueness and constant borrowing from other disciplines such as medicine. Standish (2002) maintains that nursing should maintain disciplinary borders, cross them of course, but ultimately seek to preserve a discreet body of work that both underpins and expands the discipline.

Nursing has grown as an academic discipline over the past decade and UK nurses are now increasingly likely to be qualified at graduate level and many undertake higher degrees and doctorates. At the point where nursing as an academic discipline is beginning to thrive, Watson and Thompson (2004) suggest that it is in danger of going backwards, returning to the task orientated approach of the 1960's and 70's. Task orientated training enabled students to understand individual mechanical processes but many missed the, 'big picture'. They learned a 'bunch of techniques, but to them they were just that; a bunch of techniques' (Kennedy 1998 p142). At undergraduate level, the emphasis of the nursing curriculum is increasingly directed toward 'trainability'. Academics in a still emerging discipline, such as UK nursing, are firmly directed, at undergraduate level, towards a skills based agenda, which, it can be argued, subjugates the 'substantive content of academic disciplines to technical and bureaucratic procedures' (McNamara 2006 p 471). Yet Universities are concerned not only with teaching and research but with the advancement of teaching within a scholarship framework. Through the work of scholars such as Boyer (1990) teaching has advanced as a wider scholarly discipline, a discipline that moves forward as the result of the integration of research, synthesis and application to practice (Thompson 2006). 
In the past, nurses who wished to become academics made a 'linear transition' from the UK National Health Service into education (Kenny et al 2004 p630). Traditionally, a close relationship between the Health Service and education ensured a supply of potential teachers who were rooted firmly within the practice arena. A decade ago, the role of nurse educator was more clearly defined, with the main task centred on the production of a trained workforce for the clinical area. Movement out of the clinical sector and into education in the 1990's has had a profound effect on nurse educators, now they are required to focus more on their academic profile, many perceiving this as leading to an inevitable loss of clinical credibility (Kenny et al 2004). 


\section{Developing academic identity}

Clark et al (2002) suggest that Universities should help novice academics develop 'a breadth of vision that will allow them to embrace new and innovative ways of teaching and learning, in a dynamic and evolving higher education environment' (p129). Starting an academic career can be complex and challenging. Snyder (1997) suggests that professional competence implies not just a level of attainment linked to professional qualification but a career long approach to knowledge building. Making the transition from clinician to educator or in fact, increasingly, maintaining and managing a dual role with a foot in each camp, presents novice nurse academics with an added complication (Andrew and Wilkie 2007). Entering academia from a background that may be rich in practice experience but limited in teaching and research means that new academics experience culture shock. Practitioners who join the academic community sometimes struggle to come to terms with what is effectively a career change (Diekelmann 2004). There are reports in the literature of qualitative studies where findings reveal feelings of loss, inadequacy and lack of fluency in a new and sometimes alien culture (Diekelmann 2004, McArthur-Rouse 2008).

In professions such as nursing and teaching, much of the learning is centred on a way of being or tacit knowledge, which, although not explicit, is often the way that individuals develop professional ways of knowing (Booth et al 2007). Becoming an academic involves a socialisation process that leads the individual on a journey, either moving from one organisation to another, or often requiring them to span two organisational cultures, one, clinical and known territory, the other educational and unknown (Andrew et al 2008). The need to create a learning culture within higher education for academics as well as students is a pre-requisite for professional/personal growth and development of novice nurse educators (Kenny et al 2004). Becoming an academic involves a socialisation process that leads the individual on a journey, either moving from one organisation to another, and often requiring them to span two organisational cultures, one, clinical and known territory, the other educational and unknown (Andrew and Wilkie 2007).

\section{Communities of Practice}

Wenger et al (2002) believe that professional learning and development are about communities, their identities and their practice. Wenger (1998) blends a constructivist view of learning, where meaningful experience is set in the context of personal development with the 
practitioner's 'relationship with a wider but identifiable group of people' (Fowler and Mayes 1999 p7). The result is an integrated approach to learning, achieved through a combination of social engagement and collaborative working in an authentic practice environment.

CoPs can provide a potentially useful framework for constructing collaborative learning. Lai et al (2006) highlight the fact that CoPs are situational and rooted in practice. They argue that they are not just managed knowledge networks; although there are similarities and that they are more than information exchanges, although they do share information. CoPs are more purposeful. They are grounded in the deep interest of their members, encouraging them to share personal histories and journeys, weaving a narrative, to contextualise professional and practice development. Novices can mix with experts, academics with practitioners and mentors with the mentored (Lave and Wenger 1991, Booth 2007). Wenger's (1998) CoPs learn through the act of social participation. He strongly identifies with the concept of active group learning and collaboration in an authentic practice environment. Membership of a CoP engages the individual in the process of being active participants in the practices of social communities and constructing identities in relation to these communities' (Wenger 1998 p4). According to Wenger et al (2002), CoPs can range in size, they can be long or short lived, co-located or distributed, within or without the organisation, local or international, organised or spontaneous, hidden or institutional. CoPs can have diverse memberships and exist in virtual or real time. They thrive or die according to the commitment of their members (Wenger et al 2002). In a similar fashion, the model of shared leadership designed by Bligh et al (2006), a CoP is underpinned by an environment that is ripe for growth, propelling the person from 'individual level dependence' to team focussed levels of 'trust, potency and commitment' (p300).

Individuals are primarily motivated to join a CoP to develop a sense of professional identity and belonging. A CoP forms or is formed around groups of people who share a common concern or interest and who wish to 'deepen their knowledge and expertise' in a particular subject or discipline (Wenger et al 2002 p4). The community acts as a vehicle for collaboration, allowing members to enter dynamic and engaged relationships with colleagues and others. McNeil (1997), in a study investigating the transition from nurse to teacher, stresses the need for the development of professional identity and Booth et al (2007) believe that to enable the development of practice, individuals need to explore of knowledge that is both tacit as well as explicit. A CoP can complement formal training programmes, by allowing members to explore the pedagogical underpinning of practice and share less formal, tacit, personal survival knowledge. 


\section{Community working}

Drawing on their prior experience of implementing communities within the workplace (Buggy et al 2004, Andrew et al 2008), in 2008 a small team from Glasgow Caledonian University, School of Nursing, Midwifery and Community Health conceived and implemented iCoP, a project intended to pilot an international online CoP to engage novice nurse educators. It was implemented via a secure weblog and underpinned by supportive web pages. The community was moderated through the host institution and potential members invited to subscribe. Although not intended or implemented as a research project, an action approach was adopted. In keeping with this, all members consented to a planned dissemination process and periodic ethical advice and guidance was sought and given by the Chair of the School Research Ethics Committee.

The project was designed to explore the potential of an experiential international online CoP for novice educators, focussed on the development of professional identity in teaching. The study of the effects of group heterogeneity, in particular groupings of individuals of differing ethnic and cultural origins' is currently gaining momentum in the literature (Yiannis and Griffiths 2008). The issue of national/cultural identity contextualised to learning and teaching in nursing was an area that interested the team. Reflecting the findings of Wenger et al (2002), the CoP was facilitated by a community coordinator, who was a member of academic staff from the host institution. The role of community coordinator is considered to be pivotal. Wenger et al (2002) recommend this role to promote continuity and sustainability in the longer term. It should be stated that previous community coordination had only been undertaken on a national (Scottish) basis and that no member of the team had experience of international moderation.

Over a six month period, the CoP attracted members from Canada, Northern Ireland, Portugal, Italy, The Netherlands, Cyprus, Czech Republic, Denmark, England and Scotland. The language of the community was English. There are inherent challenges when attempting to create and sustain heterogeneous groups. There is some evidence in the literature to suggest that heterogeneous groups are easier to work in, may achieve results more quickly and are more sustainable in the longer term (Yiannis and Griffiths 2008). By contrast homogenous groups of are more likely to lapse into the 'Apollo Syndrome' described by Belbin (1993) where teams of highly creative individuals collectively perform badly. This is thought to be because of the number of dominant individuals within the one 
group, who spend time trying to persuade other members to adopt their own view, rather than valuing or encouraging individual opinions (Belbin 1993; Yiannis and Griffiths 2008).

The CoP attracted fourteen members, not all were active continuously and some remained peripheral or passive throughout (Wenger 1998). Members were encouraged to explore the transition from practice to education. Reflecting Wenger (1998) and Wenger et al (2002) membership also included experienced academics to ensure that the community reflected a breadth of knowledge and professional know-how. This mix was intended to promote and encourage rich dialogue through the interaction of novices with each other and more experienced colleagues via an online mentoring/coaching environment. This community interacted (periodically) over a period of six months discussing the transition from practitioner to educator.

\section{Community thinking}

Weblog mediated conversations are 'a series of interlinked weblog posts and comments on a specific topic' (Efimova and de Moor 2005:1). Analysing a weblog community allows the coordinator to examine the narrative rhythm, pattern and linking practices of members to support a basic content analysis (Efimova and de Moor 2005). Unlike formal research approaches this CoP was underpinned by a 'model of informal group opinion' which is not 'the sum of individual opinions but the product of collective interactions' (Mangold $1960 \mathrm{p}$ 49). Mangold (1960) developed the concept of group opinion linked to the empirical evidence of a collective' and the approach to and analysis of this CoP largely reflects this model (Bonsack 2004:215).

New academics, wherever they were geographically located, initially 'mourned' their loss of clinical expertise (Andrew et al 2008). More experienced colleagues however, recognised that, rather than a loss of expertise, it was progressively the nature of that expertise that changed. As academics acclimatised, clinical knowledge was transferred into and applied to an educational rather than a practice environment. Overall members recognised that moving into education often amounted to a career change. There was discussion regarding the maintenance of clinical currency. All members recognised that maintaining a clinical profile was challenging and a proportion acknowledged that clinical/practice integration was often achieved through close collaboration with mentors rather than direct clinical contact. Unlike the United Kingdom (UK), in parts of Europe, becoming an academic is regarded as a 
different profession, therefore lessening the emphasis on clinical involvement. Those individuals who spanned both practice and educational environments recognised the inherent tensions involved when attempting to address the (often different) priorities of two organisations (Andrew and Wilkie 2007). The need to carry out research and publish as part of the role was also discussed. The balance of teaching and research is not only a national issue but is also recognised internationally as a challenge.

Members enjoyed the experience of linking with other teachers throughout Europe and beyond. They did not rate language as a barrier; rather they perceived joint collaboration with other countries in an extremely positive fashion. The advantages of the online CoP were detailed as being the practice orientated nature of the communication, easy accessibility online, flexible communication, learning from other worlds and perspectives. In the longer term members felt that this community could facilitate research collaboration networks and academic/professional development. The main problems identified were time zone issues from member's outwith Europe, lack of community focus at times, the difficulty of heterogeneous working and the challenges of online communication for a profession who are traditionally more accustomed to working in a face to face environment.

\section{Limitations}

Keeping community members engaged and on board is difficult. In this CoP some individuals joined but through work priories, became peripheral or passive. Wenger et al (2002), however point out that just because a member is passive does not mean that they are not deriving some benefit from studying the interactions of others. The communication tended to be periodic in nature throughout. This was, in part, due to time delay and time zone issues, however the time required to moderate and nurture the community was underestimated at the outset and was also contributing factor. It was anticipated that after an initial period of close support, peer support would effectively carry the process with reduced moderation required. This did not really occur, underpinning the need for robust and continuous moderation/coordination.

\section{Discussion}

The debate regarding the status of nursing academics is not just confined to the UK. The question of whether nurse educators should be predominately located in practice or academia is debated in the national and international literature (Thompson and Watson 
2001, Scott 2008). Although nursing in the UK has moved into higher education, there is 'a danger that the traditional view of nurse educators' role and function has not changed' (Kenny et al 2004 p 630). McNamara (2006) has shown that for some critics this may be a view to be commended rather than condemned. The consequences, however, of continuing to promote the opinion that educators in nursing are there solely as 'passive implementers of nurse education' will be to curtail academic advancement, to the detriment of the both the profession and the institution (Kenny 2004 p 630).

CoPs invite people to become part of a group, sharing a common purpose or passion. CoPs can also provide a portal for knowledge development, management and dissemination. In professions such as teaching and nursing, knowledge may be more tacit than explicit, linked to the development of a professional identity. Workplace communities provide fertile ground for the evolution of personal and professional practice development, allowing groups of individuals to collaborate and share their experiences. A CoP can nurture the skills and talents of like and diverse populations. These different attributes can be harnessed to challenge and develop professional teaching practice. iCoP encouraged novice educators to collaborate with each other across continents and time zones. The project was valuable both to uncover international opinion regarding the transition from practice to education and to explore the challenges, benefits and limitations of online community working.

\section{Conclusion}

This paper has prompted a broader exploration of the literature to inform the potential use of CoPs in the development of professional identity in teaching within the discipline of academic nursing. The continuing debate that questions the validity of nursing as a discipline within UK HE means that we continue to question, not only where nursing should be located but whether nurses are contributing on equal terms with other academics to the development of an evolving body of knowledge defined by strong disciplinary boundaries. Nursing continues to struggle to articulate its uniqueness and the aspirational scholarly agenda, to a certain extent, remains aspirational. There is as yet no definitive way forward for academic nursing and no blueprint for the ideal academic. Novices internationally struggle with the tensions of a dual identity and continue to debate the amount of clinical contact required. The use of experiential innovations such as iCoP however can support transference by promoting collaboration and peer support allowing new academics to work through the 
issues and challenges of developing an identity in education; contributing to an expansion of innovation and excellence in teaching and learning. 


\section{References}

Andrew, N., Tolson, D. \& Ferguson, D. 2008. Building on Wenger: communities of practice in nursing. Nurse Education Today, 28(2): 246-252.

Andrew, N. \& Wilkie, G. (2007) Integrated scholarship in nursing: and individual responsibility or collective undertaking. Nurse Education Today:27:1-4.

Belbin, R. M. (1993) Team roles at work. Oxford, UK: Butterworth.

Bligh, M.C., Pearce, C.L. \& Kohles, J. C. 2006. The importance of self- and shared leadership in team based knowledge work. Journal of Managerial Psychology 21(4): 296-318.

Booth, J., Tolson, D., Hotchkiss, R. \& Schofield I. 2007. Using action research to construct national evidence-based nursing care guidance for gerontological nursing Journal of Clinical Nursing 16: 945-953.

Bohnsack, R. (2004) Group discussion and focus groups. In Flick, U.,Von Kardorff, E., \& Steinke, I. (Eds). A companion to qualitative research. London: SAGE.

Boyer, E. L. 1990 Scholarship reconsidered: priorities of the professoriate. Princeton, New Jersey: Carnegie Endowment for the Advancement of Teaching.

Buggy, T., Andrew, N., Tolson, D. \& Macgee, M. (2004) Evaluation of a virtual practice development college for nurses. BCS, ITIN, British Journal of Computing 16(3): 4-8.

Butler, M., Treacy, A., Scott, A., Hyde, P., MacNeela, K., Irving, A., Byrne, A. \& Drennan, J. 2006. Towards a minimum data set for Ireland: making Irish nurses visible. Journal of Advanced Nursing 5(3): 364-375.

Clark, G., Healy, M., Jenkins, A., Wareham, T., Chalkley, B., Blumhof, J., Gravestock, P. Honeybone, A., King, H. \& Thomas, N. 2002. Developing new lecturers. Active Learning in Higher Education 3(2): 128-144.

Diekelmann, N. 2004. Experienced practitioners as new faculty: new pedagogies and new possibilities, Journal of Nursing Education, 43(3): 101-103.

Efimova, L. \& de Moor, A. (2005) Beyond personal web publishing: An exploratory study of conversational blogging practices. Proceedings of the $38^{\text {th }}$ International Conference on System Sciences (ICSS-38), IEEE Computer Society Press, 3-6. Available from: http://blog.mathemagenic.com/2004/09/15/beyond-personal-webpublishing-anexploratory-study-of-conversational-blogging-practices/

Fowler, C. J. H. \& Mayes, J. T. 1999 Learning relationships; from theory to design. Association for Learning Technology, 7(3), 6-16.

Gabriel, Y. \& Griffiths, D.S. International Learning Groups: synergies and dysfunctions. Management Learning, 39(5): 503-518. 
Kennedy, P.E. 1998. Using Monte Carlo studies for teaching econometrics. In Becker, W. \& Watts, M. Teaching economics to undergraduates: alternatives to chalk and talk. Cheltenham: E. Elgar.

Kenny, G., Pontin, D and Moore, L. 2004. Negotiating socialisation: the journey of novice nurse academics into higher education. Nurse Education Today 24(8): 629-637.

Lai, K.W., Pratt, K., Anderson, M. \& Stigter, J. 2006. Literature review and synthesis: online communities of practice. Ministry of Education, New Zealand. Available from: www.minedu.govt.nz.

Lave, J. \& Wenger, E. 1991. Situated learning, legitimate peripheral participation, Cambridge: University of Cambridge Press.

Luby, T. 2006/7. Developing professional knowledge within a community of practice: questions for Scottish teachers for a new era. Education in the North 14: 24-31.

Mangold, W. (1960) Gegenstand und Methode des Gruppendiskussionsverfahrens Frankfurt a. M.: Europaische Verlagsanstalt.

McArthur-Rouse, F. 2008. From expert to novice: an exploration of the experiences of new academic staff to a department of adult nursing studies, Nurse Education Today 28: 401-408.

McNamara, M.S. 2008. Of bedpans and ivory towers. Nurse academics identities and the sacred and profane: A Bernsteinian analysis and discussion paper. International Journal of Nursing Studies 45(3), 458-470.

Meyer, H.F. \& Land, R. 2005. Threshold concepts and troublesome knowledge (2) Epistemological consideration and a conceptual framework for teaching and learning. Higher Education 49: 373-388.

Miers, M. 2002. Nurse education in higher education; understanding cultural barriers to progress. Nurse Education Today 22: 212-219.

Scott, D.S. 2008 New professionalism - shifting relationships between nursing education and nursing practice. Nurse Education Today 28: 240-245.

Snyder, W. 1997. Communities of practice: combining organisational learning and strategy insights to create a bridge to the $21^{\text {st }}$ Century, Available From: www.co-i-I.com.

Standish, P. 2002. Disciplining the profession: subjects subject to procedure. Educational Philosophy and Theory 34(1): 5-23.

Watson, R. and Thompson, D.R. 2004. The Trojan horse of nurse education. Nurse Education Today 24: 73-75.

Wenger, E. 1998. Communities of practice: learning meaning and identity ( $6^{\text {th }}$ ed) Cambridge University Press: Cambridge. 
Wenger, E., McDermott, R. \& Snyder, W. 2002. A guide to managing knowledge. Cultivating communities of practice. Boston, Massachusetts: Harvard Business School Press.

Thompson. D.R and Watson, R. 2001. Academic nursing - what is happening to it and where is it going. Journal of Advanced Nursing, 36(1): 1-2.

Thompson, D.R. 2006. Professors of nursing: what do they profess? Nurse Education in Practice 6: 123-126. 